Revisão

\title{
Ciclones em Superfície nas Latitudes Austrais: Parte I - Revisão Bibliográfica
}

\author{
Michelle Simões Reboita ${ }^{1}$, Manoel Alonso Gan ${ }^{2}$, Rosmeri Porfírio da Rocha ${ }^{3}$, \\ Igor Stivanelli Custódio ${ }^{1,3}$ \\ ${ }^{1}$ Instituto de Recursos Naturais, Universidade Federal de Itajubá, Itajubá, MG, Brasil. \\ ${ }^{2}$ Instituto Nacional de Pesquisas Espaciais, São José dos Campos, SP, Brasil. \\ ${ }^{3}$ Departamento de Ciências Atmosféricas, Universidade de São Paulo, São Paulo, SP, Brasil.
}

Recebido em 10 de Março de 2016 - Aceito em 15 de Fevereiro de 2017

\begin{abstract}
Resumo
Com o objetivo de organizar o conhecimento sinótico sobre ciclones em superfície em latitudes austrais, este trabalho (o primeiro de um conjunto de dois) apresenta uma síntese das principais características de quatro tipos de ciclones: extratropical do tipo Bjerknes e Solberg, extratropical do tipo Shapiro e Keyser, tropical e subtropical. Ao longo do texto são apresentados modelos conceituais bem como os mecanismos de ciclogênese, intensificação e ciclólise de cada tipo de ciclone. As principais diferenças entre os quatros tipos de ciclones em superfície estão nas estruturas horizontais e verticais dos campos de temperatura e vorticidade relativa.
\end{abstract}

Palavras-chave: ciclones extratropicais, ciclones subtropicais, ciclones tropicais, ciclo de vida, Hemisfério Sul.

\section{Surface Cyclones over Austral Latitudes: Part I - Bibliographic Review}

\begin{abstract}
The purpose of this study is to summarize the main synoptic features of four types of cyclones: extratropical cyclone following Bjerknes and Solberg model, extratropical cyclone following Shapiro and Keyser model, tropical and subtropical. We present some conceptual models and mechanisms of cyclogenesis, intensification and cyclolisis of each cyclone kind. The main differences between the four types of cyclones in surface are the horizontal and vertical structures of temperature and relative vorticity fields.
\end{abstract}

Keywords: extratropical cyclones, subtropical cyclones, tropical cyclones, life cycle, Southern Hemisphere.

\section{Introdução}

O termo ciclone é usado para fazer referência aos sistemas de tempo com rotação associada a áreas de baixa pressão na superfície (Petterssen, 1956). A nomenclatura extratropical distingue os ciclones formados nos extratrópicos dos formados nos trópicos, cuja gênese é diferente. O processo de formação ou intensificação de um ciclone é denominado ciclogênese, enquanto que sua dissipação, ciclólise.

A formação e o comportamento dos ciclones extratropicais vêm sendo estudados desde o século XIX, devido às alterações nas condições de tempo que esses sistemas provocam nas regiões onde atuam. O primeiro modelo conceitual mais realístico dos ciclones extratropicais foi proposto por Bjerknes (1919) e Bjerknes e Solberg (1922). Nestes estudos, a formação dos ciclones extratropicais foi associada à presença de gradientes horizontais de temperatura em superfície (isto é, associado a uma zona baroclínica) e o aprofundamento do ciclone ocorre com a rotação da frente fria em torno do centro de baixa pressão até que a mesma alcance a frente quente, que tem menor velocidade de deslocamento do que a frente fria. Na década de 1990, Shapiro e Keyser, estudando casos de ciclogêneses com rápida intensificação, verificaram que em alguns ciclones a frente fria deslocava-se perpendicular à frente quente de forma que essas, geralmente, não se encontravam. Com isso, surgiu outro modelo conceitual de ciclones, o chamado modelo de Shapiro e Keyser. É importante ressaltar que o modelo desses autores não substitui o modelo de 
Bjerknes e Solberg, ou seja, é um modelo adicional que descreve as características de ciclones que são diferentes das do primeiro modelo desenvolvido. Uma descrição mais detalhada dos modelos de Bjerknes e Solberg e de Shapiro e Keyser será apresentada na seção 2.1.

Com relação aos ciclones tropicais, o estudo desses sistemas ganhou notoriedade entre as décadas de 1940 a 1960 com os trabalhos de Riehl (1948), Ramage (1959) e Gray (1968). A gênese dos ciclones tropicais não resulta da existência de gradientes horizontais de temperatura em superfície como a dos ciclones extratropicais e, sim, da combinação da presença de anomalias ciclônicas em superfície e da liberação de calor latente proveniente da evaporação dos oceanos tropicais (Palmén, 1956; Gray, 1968; Emanuel, 1991). Portanto, quando um ciclone tropical atinge a superfície continental sua fonte de energia, em geral, cessa e o sistema enfraquece, podendo dissipar ou se transformar em um ciclone extratropical, dependendo das condições sinóticas.

Por mais de meio século, a comunidade científica acreditou apenas na existência dos ciclones extratropicais (Bjerknes, 1919; Bjerknes e Solberg 1922; Charney 1947; Eady, 1949; Buzzi e Tibaldi, 1978; McGinley, 1982; Buzzi et al., 1987; Gan e Rao, 1994) e tropicais (Palmén, 1956; Gray, 1968, por exemplo), mesmo que alguns estudos, como o de Gray (1968), já mencionassem a existência de ciclones subtropicais, que são sistemas com características tanto de tropicais quanto extratropicais e, por isso, também denominados de híbridos.

Foi com o estudo de Hart (2003) que os ciclones subtropicais voltaram a ser foco de pesquisa. Hart (2003) desenvolveu um diagrama chamado Cyclone Phase Space (CPS) que descreve a estrutura térmica tri-dimensional dos ciclones através do cálculo de perturbações de altura geopotencial num raio a partir do centro desses sistemas. Dessa forma, o diagrama mostra que um ciclone pode ter sua gênese na categoria de tropical, subtropical ou extratropical e que pode evoluir de uma categoria para outra. Por exemplo, um ciclone pode se originar como extratropical, passar pela fase subtropical e decair como tropical como foi o caso do Furacão Catarina ocorrido em 2004 no sudoeste do oceano Atlântico Sul (McTaggart e Cowan, 2006). Nota-se, portanto, que um ciclone não se transforma de extratropical para tropical, ou vice-versa, sem passar por uma fase intermediária (subtropical), o que fornece a ideia de continuиm.

Vários trabalhos têm sido dedicados ao estudo das características climatológicas dos ciclones tropicais (Sugi et al., 2002; Shephered e Knutson, 2007; Zhao et al., 2009; Knutson et al., 2010; Ramsay et al., 2012), extratropicais (Gan e Rao, 1991; Sinclair, 1994, 1995; Simmonds e Keay, 2000 a-b; Hoskins e Hodges, 2005; Reboita et al., 2010; Reboita et al., 2014) e subtropicais (Guishard e Evans, 2009; Evans e Braun, 2012; Cavicchia et al., 2014; Gozzo et al., 2014). Já, outros, destinam-se a análise das características sinóticas de casos de ciclones. Alguns exemplos para o sudoeste do oceano Atlântico Sul e considerando os sistemas extratropicais são Gan e Rao (1996), Seluchi et al. (2001), Reboita et al. (2009), Iwabe e da Rocha (2009), Piva et al. (2008, 2011), Dias Pinto e da Rocha (2011) e Gozzo e da Rocha (2013); considerando os subtropicais são Mathias (2012), Dias Pinto et al. (2013) e Gozzo et al. (2014) e, por fim, considerando os tropicais são McTaggart e Cowan, (2006) e Mathias (2012).

Embora a literatura possua estudos de casos para os diferentes tipos de ciclones, são escassos os que num mesmo trabalho mostram didaticamente as diferenças na estrutura sinótica deles. A fim de compilar e apresentar de maneira clara as características sinóticas de quatro tipos de ciclones em superfície, esse primeiro artigo, de um conjunto de dois, tem como finalidade apresentar uma revisão do processo de gênese e ciclo de vida dos ciclones extratropicais (tipo Bjerknes e Solberg e tipo Shapiro e Keyser), tropicais e subtropicais. Já o segundo artigo enfoca: (1) o estudo de caso de cada tipo de ciclone, a fim de mostrar suas principais características sinóticas e (2) uma caracterização de cada tipo de ciclone através do CPS.

\section{Tipos de Ciclones}

\subsection{Ciclones extratropicais}

\subsubsection{Ciclo de vida dos ciclones extratropicais}

A principal característica do modelo ciclônico proposto por Bjerknes, em 1919, é a existência de duas linhas de confluência dos ventos em superfície saindo do centro do ciclone, separando duas massas de ar com propriedades térmicas distintas, e denominadas de squall line e steering line (Fig. 1). Ambas as linhas de convergência são precedidas por uma região de divergência.

As investigações de Bjerknes continuaram e, em 1922, juntamente com a colaboração de Solberg (Bjerknes e Solberg, 1922), mostraram que os ciclones extratropicais

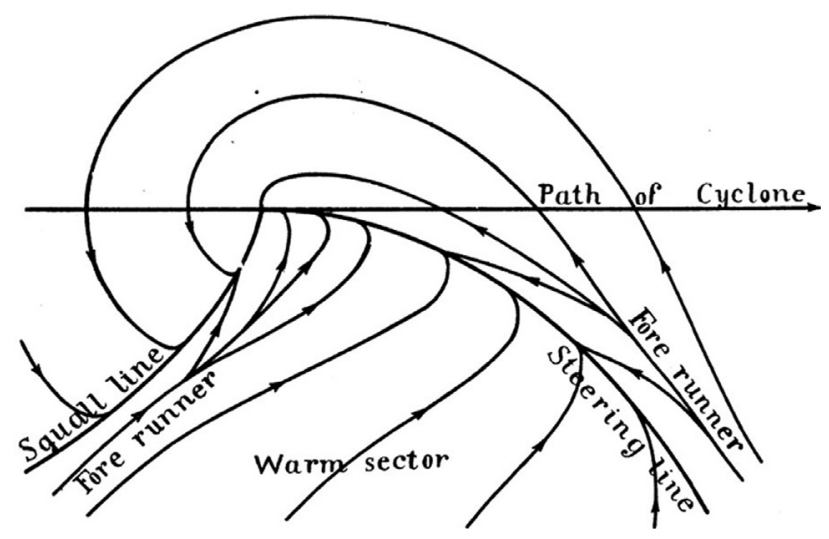

Figura 1 - Linhas do escoamento num ciclone em movimento no $\mathrm{He}$ misfério Norte. Na figura, warm sector indica setor quente, path of cyclone corresponde ao sentido de deslocamento do sistema, squall line e steering line indicam regiões de convergência e fore runner fornece a ideia de um corredor do escoamento. Adaptado de Bjerknes (1919). 
possuem um ciclo de vida com vários estágios característicos e que aquele proposto em 1919 era apenas uma fase do ciclo de vida. Portanto, os ciclones se formam, intensificam, atingem a maturidade e decaem até dissipar. Nesse trabalho, Bjerknes e Solberg definiram a frente polar como sendo uma linha que separa o ar frio de origem polar, do ar quente das altas subtropicais (o que ocorre, principalmente, entre $35^{\circ}-55^{\circ}$ de latitude em ambos os hemisférios). Assim, a squall line passou a ser denominada de frente fria e a steering line, de frente quente. A mudança nos nomes foi devido ao fato do termo steering line ser ambíguo e levar a enganos. O modelo de Bjerknes e Solberg (1922) foi denominado de Teoria da Frente Polar, pois propôs que os ciclones de latitudes médias se formam como resultado da interação de duas massas de ar: uma de origem polar e outra de origem tropical.

No modelo conceitual de Bjerknes e Solberg (Fig. 2), o ciclone se forma em uma pequena onda que surge ao longo de uma frente em superfície, devido ao ar frio (quente) invadir o vértice da onda, propagando-se em direção ao equador (polo) (Fig. 2b). Esta mudança ocasiona um reajustamento no campo de pressão que resulta em isóbaras quase circulares, com um sistema de baixa pressão centrado no vértice da onda. No Hemisfério Sul, o vento de oeste converte-se em ventos de noroeste, empurrando a parte leste da frente para o sul, denominada frente quente, e a parte oeste da onda desloca-se para o norte-nordeste como frente fria (Fig. 2b). Como a frente fria se propaga mais rapidamente do que a frente quente (pois o ar frio é mais denso, o que influencia a força do gradiente horizontal de pressão), à medida que essa se move ao redor do centro do ciclone, começa a se aproximar da frente quente. Quando parte da frente fria alcança o ar frio na retaguarda da frente quente (Fig. 2e) ocorre o aprisionamento do ar quente na forma de uma "ilha" no centro do ciclone, fenômeno denominado de seclusão (ou em inglês, seclusion). À medida que a frente fria se desloca, a "ilha de ar quente" diminui de tamanho, fazendo com que o ar quente no centro do sistema gradativamente desapareça (isto é, ele ascende para níveis mais alto até sair completamente do sistema), de forma que predomine apenas ar frio no ciclone em superfície. Quando não há mais ar quente em superfície, apenas em altitude, o ciclone é denominado de ocluso (Fig. 2f) e é nesse estágio que ele alcança sua intensidade máxima. Após o ciclone se torna um vórtice frio e simétrico (Fig. 2g), e, como não há mais fonte de energia (ar quente/gradiente de temperatura) disponível, o ciclone tende a desaparecer (Fig. 2h).

O desenvolvimento do ciclone mostrado na Fig. 2 também pode ser representado através de perfis verticais de temperatura do ar traçados ligeiramente a norte do centro do ciclone e considerando a direção leste-oeste (Fig. 3). Na figura, as linhas tracejadas indicam as descontinuidades do campo de temperatura e as linhas contínuas indicam as isotermas, que estão paralelas à superfície terrestre. $\mathrm{Na}$ região de ar quente, as isotermas estão mais afastadas da superfície, enquanto na região de ar frio, mais próximas. Isso significa que se a espessura da camada fosse calculada entre a superfície e um nível de pressão constante, essa seria maior no lado quente do que no lado frio. Ainda na Fig. 3,
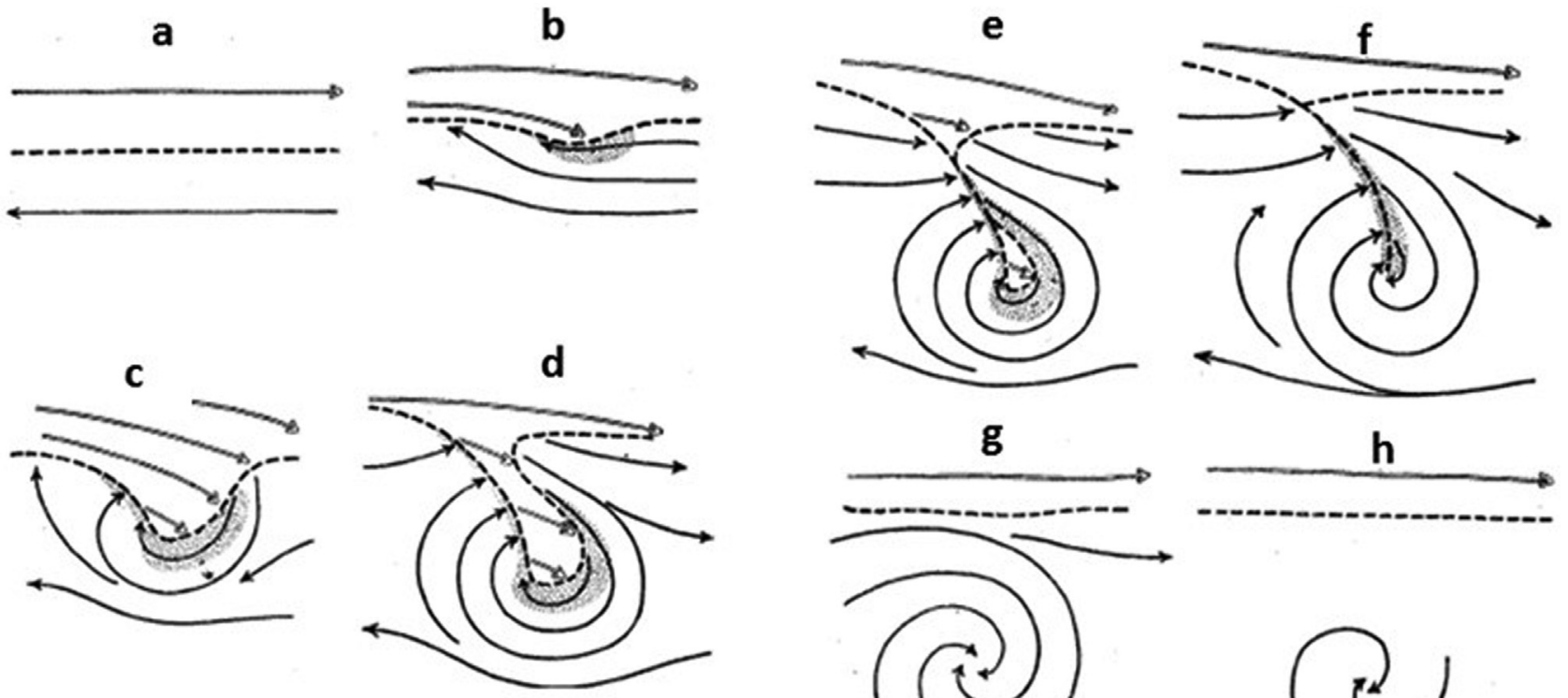

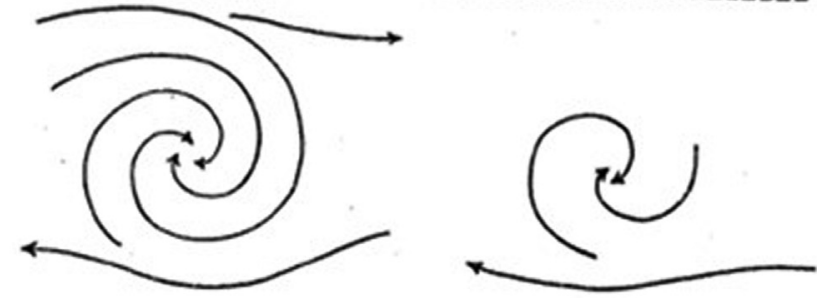

Figura 2 - Ciclo de vida dos ciclones extratropicais considerando o Hemisfério Sul: a) escoamento estacionário, b) perturbação inicial do escoamento, c-d) crescimento da perturbação ciclônica (ciclone), e) perturbação ciclônica iniciando a oclusão e com uma pequena seclusão de ar quente, f) oclusão atinge máxima intensidade, g) ciclone totalmente ocluído e h) decaimento do sistema. Adaptado de Bjerknes e Solberg (1922). 


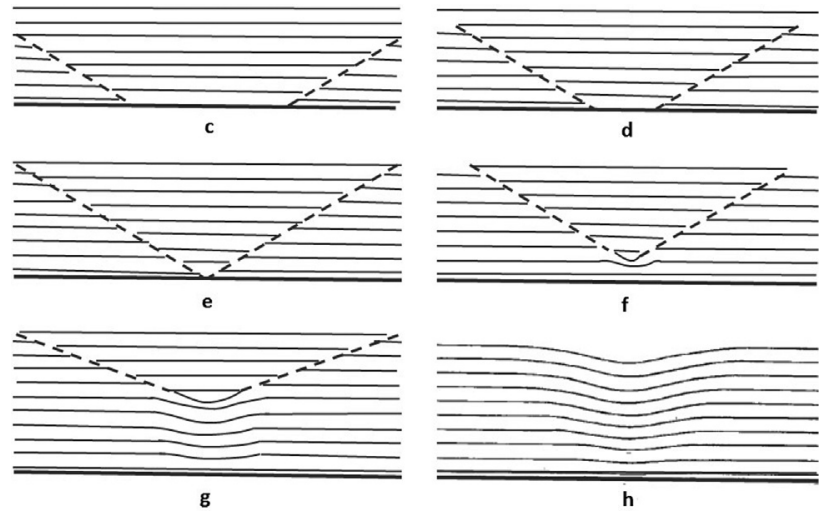

Figura 3 - Esquema de perfis verticais da temperatura do ar correspondentes aos estágios do ciclo de vida de um ciclone extratropical mostrado na Fig. 2 (as letras na presente figura indicam os mesmos estágios do ciclo de vida do ciclone mostrado na Fig. 2). As linhas contínuas indicam as isotermas e as tracejadas, descontinuidades. Fonte: Bjerknes e Solberg (1922)

tem-se que $\mathrm{o}$ ar frio possui temperatura similar à esquerda $\mathrm{e}$ direita da região com ar quente.

Da gênese ao momento da oclusão (Fig. 2a-f e 3c-f), o ar quente ascende, sendo levantado por duas "cunhas" de ar frio, que gradualmente se aproximam uma da outra. Como mencionam Bjerknes e Solberg (1922), esse processo transforma parte da energia potencial armazenada no sistema em energia cinética. Assim, todo o ciclone que ainda não ocluiu (Fig. 2f, 3f) tem energia potencial disponível para seu desenvolvimento. Após o encontro das duas "cunhas" de ar frio em superfície, o ar quente remanescente sobrepõe $o$ ar frio. Nesse momento ainda existe energia potencial disponível, mas essa decresce à medida que o ar mais quente, ao ascender, resfria adiabaticamente. Entretanto, quando o ciclone se torna um vórtice com temperatura do ar homogênea, não existe mais energia potencial disponível para ser convertida em cinética. Nesse período, o movimento do sistema pode ser mantido somente pela inércia do movimento das massas de ar.

Como já mencionado, após a oclusão ainda há um período em que o ciclone produz energia cinética, entretanto, em baixos níveis outro processo vai consumir sua energia, a fricção. Além da fricção, o ciclone perde energia cinética para o estado básico através de conversão barotrópica (Randel e Stanford, 1985) e parte desta pode ser também exportada corrente abaixo através dos fluxos ageostróficos (Orlanski e Katzfey, 1991). Dessa forma, após o estágio de oclusão o ciclone irá enfraquecer e desaparecer. Com relação à oclusão, essa pode ser do tipo fria ou quente. A oclusão fria ocorre quando o ar frio na retaguarda da frente fria é mais frio do que o ar da região onde terá a oclusão, por outro lado, na quente, $o$ ar frio da retaguarda da frente fria é menos frio do que o ar da região onde terá a oclusão. Em termos da propagação dos ciclones extratropicais, essa ocorre em direção ao setor quente da onda ciclônica.
Na época dos estudos de Bjerknes e colaboradores ainda não se conheciam os mecanismos de acoplamento entre a circulação em superfície e em altos níveis. Com o advento da radiossonda, na década de 1930, foi possível conhecer a estrutura tri-dimensional da atmosfera e, com isso, o modelo de Bjerknes e Solberg (1922) foi unificado com o conhecimento da atmosfera superior para explicar a gênese dos ciclones extratropicais. Entretanto, antes de abordar esse modelo conceitual é interessante destacar que também foi Bjerknes (1937) que elucidou o desenvolvimento da divergência de massa em níveis superiores (Palmén e Newton, 1969). Ele inferiu, com o auxílio da relação do vento gradiente, que em níveis mais altos da atmosfera há divergência no setor leste dos cavados e convergência no setor oeste e o inverso para regiões de cristas. Entretanto, os resultados completos deste estudo só foram publicados em 1944 com a colaboração de Holmboe.

Em 1947, Sutcliffe propôs que o desenvolvimento de ciclones e anticiclones poderia ser deduzido por expressões simplificadas, as quais medem a divergência relativa entre a média e a baixa troposfera. Os mecanismos dominantes para ciclogênese em superfície, propostos por Sutcliffe (1947), são a advecção de vorticidade absoluta em $500 \mathrm{hPa}$ e o aquecimento diferencial entre a superfície e o nível de não divergência (convencionado como $500 \mathrm{hPa}$ ). Petterssen $(1955,1956)$ deu continuidade às pesquisas de Sutcliffe, incluindo o efeito do aquecimento e resfriamento adiabático e diabático na equação de desenvolvimento de ciclones e anticiclones e, com colaboradores (Petterssen et al., 1955), formulou que o desenvolvimento dos ciclones ocorre onde e quando a advecção de vorticidade absoluta ciclônica (que é proporcional à divergência de massa) em $500 \mathrm{hPa}$ superpõe-se a uma zona baroclínica nos baixos níveis. Como a divergência de massa é encontrada corrente abaixo dos cavados, isso contribui para a retirada de massa da coluna atmosférica e redução da pressão em superfície, o que pode começar um ciclone. Os ciclones formados pela associação de ondas em níveis médios e altos da atmosfera e zonas baroclínicas em superfície são representados pelo modelo conceitual mostrado na Fig. 4 (adaptado de Celemín, 1984). Essa figura (painel da esquerda) esquematiza a evolução do ciclo de vida de um ciclone em superfície na América do Sul e sua interação com uma onda no escoamento de oeste em $500 \mathrm{hPa}$, o que fornece uma ideia da estrutura tri-dimensional da atmosfera. Para completar a ideia de estrutura tri-dimensional, são apresentados o escoamento em $300 \mathrm{hPa}$ e as frentes em superfície (Fig. 4, painel da direita). Isso permite identificar a localização do ciclone em relação aos jatos em altos níveis.

Na Fig. 4a há uma frente estacionária em superfície situada sob o setor a jusante (a leste do eixo) de um cavado em níveis médios da atmosfera. Na Fig. 4b, nota-se a configuração das frentes fria e quente em superfície. Como o cavado em $500 \mathrm{hPa}$ contribui para a redução da pressão em superfície através do processo de divergência de massa 


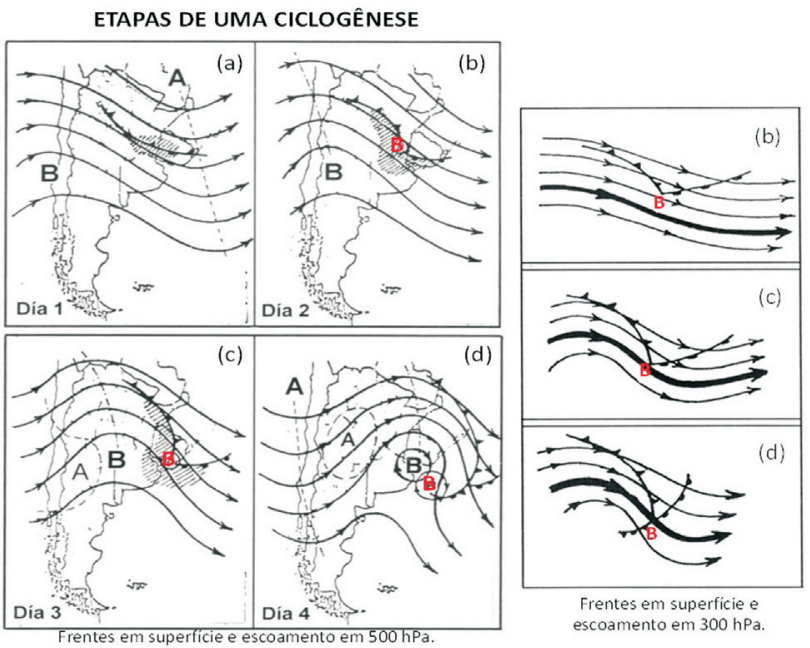

Figura 4 - Modelo conceitual do desenvolvimento de um ciclone extratropical no Hemisfério Sul. No quadro da esquerda, as linhas pretas com setas na extremidade leste representam a altura geopotencial em $500 \mathrm{hPa}$, as linhas pretas com triângulos (semicírculos) preenchidos representam as frentes frias (frentes quentes), as letras A e B negritadas em preto indicam a localização dos centros de alta e baixa em $500 \mathrm{hPa}$, respectivamente,e a letra $\mathrm{B}$ em vermelho a localização do ciclone em superfície. A região hachurada mostra a nebulosidade associada às frentes e com o ciclone. $\mathrm{O}$ quadro da direita é um complemento a ideia tri-dimensional da atmosfera, pois indica o escoamento atmosférico em $300 \mathrm{hPa}$ (linhas pretas com setas), o jato em altos níveis (linha preta mais espessa) e as frentes em superfície. A letra B também indica a posição do centro de baixa pressão. As letras (b), (c) e (d) se referem aos mesmos estágios mostrados no quadro da esquerda. Fonte: Celemín (1984).

que ocorre a sua jusante, um fraco sistema de baixa pressão em superfície surge com movimento ciclônico. Nessa fase, o centro de baixa pressão localiza-se a norte da corrente de jato em altos níveis (Fig. 4b, painel da direita). O estabelecimento da circulação em baixos níveis inicia um processo de advecção horizontal de temperatura na camada entre 1000 e $500 \mathrm{hPa}$. Assim, a leste da baixa em superfície ocorre advecção de ar quente, enquanto que a oeste, advecção de ar frio (figuras não mostradas), o que, consequentemente, aumenta a baroclinia na região das frentes quente e fria, respectivamente. De acordo com a equação de Sutcliffe (Carlson, 1991), a advecção de ar quente na coluna atmosférica na dianteira da baixa induz a criação de convergência em superfície e, portanto, vorticidade ciclônica (aqui a ideia está associada a menor densidade da camada atmosférica que facilita o escoamento para esse local), fazendo com que o sistema em superfície se desloque seguindo a máxima advecção térmica positiva. Portanto, nesse modelo o ciclone não é "carregado" no escoamento, mas reconstruído continuamente a partir do rearranjo do campo de massa em função da convergência em baixos níveis que é influenciada tanto pela divergência a jusante do cavado em altos e médios níveis quanto pela advecção de ar quente (Carlson 1991). Já no setor oeste do ciclone, a advecção de ar frio na camada contribui para aumentar a densidade do ar na retaguarda do sistema e intensificar o cavado em $500 \mathrm{hPa}$. Tanto o deslocamento do ciclone em superfície, quanto o aprofundamento do cavado são visualizados comparando a Fig. 4c com a Fig. 4b. É importante destacar que em alguns livros textos, como o de Holton (2004), não é apresentada a equação de desenvolvimento de Sutcliffe, pois essa equação pode ser substituída pela equação da vorticidade potencial, da tendência de altura geopotencial ou pela equação ômega da teoria quase-geostrófica.

Uma análise da Fig. 4c (quadro da esquerda) revela que o centro do ciclone em superfície e do cavado em níveis médios não se encontram em fase e sim com uma inclinação para oeste com a altura. Essa inclinação para oeste, em direção do ar frio, indica que o sistema está intensificando devido à conversão baroclínica de energia. Com relação ao escoamento em $300 \mathrm{hPa}$, nessa fase, o jato em altos níveis tende a cruzar o centro da baixa em superfície (Fig. 4c quadro da direita). Já a Fig. 4d (quadro da esquerda) mostra (1) o processo de oclusão do ciclone em superfície, que resulta do fato da frente fria se deslocar mais rápido do que a quente e se unir à frente quente, (2) a formação de um centro fechado de circulação em níveis médios e (3) que os centros dos sistemas em superfície e em níveis médios se encontram praticamente em fase. É comum o fechamento de centros de circulação em níveis médios e altos da atmosfera na fase de oclusão dos ciclones em superfície. Entretanto, como o centro de circulação fechada em altos níveis se forma após a existência do centro em superfície, não se pode confundi-lo com os conhecidos Vórtices Ciclônicos de Altos Níveis (VCAN). O nome VCAN é dado a centros de circulação fechada com núcleo frio cuja gênese ocorre primeiro em níveis próximos à tropopausa e que com o passar do tempo podem se prolongar para baixos níveis da atmosfera (Palmén e Newton, 1969). Outra diferença entre um VCAN e um ciclone em fase de oclusão é que o VCAN se localiza no lado equatorial das correntes de jato, enquanto que um ciclone em fase de oclusão se localiza no lado polar das correntes de jato (Palmén e Newton, 1969). Essa última característica é mostrada na Fig. 4d (quadro da direita).

Até a Fig. 4c, os processos de baixos e médios níveis (divergência a jusante do cavado em níveis médios e sob essa região convergência em superfície) interagiram para favorecer o desenvolvimento do ciclone, mas a partir da Fig. 4d vão influenciar o seu decaimento. Como os sistemas em níveis médios e altos da atmosfera se deslocam mais rápido que os sistemas em superfície (Kousky e Elias, 1982), o centro do cavado em $500 \mathrm{hPa}$ ao entrar em fase com o ciclone em superfície (mostrando uma estrutura barotrópica equivalente) não lhe favorecerá com o processo de divergência em médios/altos níveis e, portanto, com movimentos ascendentes. Além disso, no processo de oclusão, a frente fria em superfície se une com a frente quente e, com isso, o centro do ciclone em baixos níveis fica dominado por ar frio. Nesse momento ainda há ar quente em níveis mais afastados da superfície como mostra a Fig. 3f. Ar frio 
sob ar quente representa uma atmosfera estável, diminuindo a energia potencial disponível do ciclone que seria convertida em energia cinética. Logo, tem-se o decaimento do ciclone. Também é importante mencionar que nessa fase, o ciclone perde energia cinética para o estado básico devido às conversões barotrópicas (Randel e Stanford, 1985) e pode também exportar energia cinética corrente abaixo (Orlanski e Katzfey, 1991).

Com o aumento das observações meteorológicas e avanço dos modelos numéricos, verificou-se que nem todos os ciclones sobre o mar seguem perfeitamente o modelo conceitual do ciclo de vida de ciclones proposto por Bjerknes e Solberg (1922). Assim, Shapiro e Keyser (1990) propuseram um modelo com base em adaptações no modelo de Bjerknes e Solberg. Schultz e Wernli (2001) descrevem as diferenças entre os dois modelos conceituais: no modelo de Bjerknes e Solberg (1922), o ciclone evolui a partir de uma onda frontal incipiente que possui frentes quente e fria (Fig. 5aI); o aprofundamento do sistema ocorre à medida que a frente fria gira em torno do centro do ciclone, mais rápida do que a frente quente, estreitando o setor quente (Fig. 5aII,III) até chegar num momento que o ar frio toma o lugar do ar quente, o que origina a frente oclusa (Fig. 5aV). O ciclone do tipo Bjeknes e Solberg, em geral, possui a frente fria mais intensa e extensa do que a frente quente, o que lhe confere uma característica de ciclone mais extenso no sentido norte-sul do que leste-oeste.

No modelo de Shapiro e Keyser (1990), o ciclone inicia da mesma maneira do que no modelo de Bjerknes e Solberg (1922), a partir de uma onda frontal incipiente (Fig. 5bI), mas nesse caso a frente fria não gira ao redor do centro do ciclone e, sim, segue quase perpendicular à frente quente de tal maneira que não se encontra com a frente quente. Esse padrão é mostrado na Fig. 5bII e é chamado de T-bone (a forma que o sistema aparenta na carta de temperatura do ar em baixos níveis no Hemisfério Norte). Com a evolução do sistema, há um enfraquecimento no lado polar da frente fria próximo ao centro do ciclone que é chamado de fratura frontal (Fig. 5bIII). Com isso, a frente quente tende a circundar o setor oeste do centro do ciclone e, nesse setor, passa a ser denominada de bent-back front (frente curvada para trás). Na Fig. 5bIV, o ar frio circunda o ar mais quente perto do centro do ciclone, formando uma seclusão quente (warm seclusion), isto é, o aprisionamento do ar mais quente. Em geral, um ciclone do tipo ShapiroKeyser é alongado no sentido da frente quente (Fig. 5bIV).

Os modelos conceituais dos dois tipos de ciclones extratropicais são apresentados na Fig. 5; a parte inferior de cada modelo mostra o padrão da temperatura potencial em $850 \mathrm{hPa}$. Nota-se que as maiores diferenças entre os modelos ocorrem nos estágios III e IV, quando há o processo de aprisionamento de ar quente no centro do ciclone tipo Shapiro e Keyser. É interessante destacar que na Fig. 2 também foi mencionada a ocorrência de seclusão quente no ciclone do tipo Bjerknes e Solberg, mas ocorrendo na fase
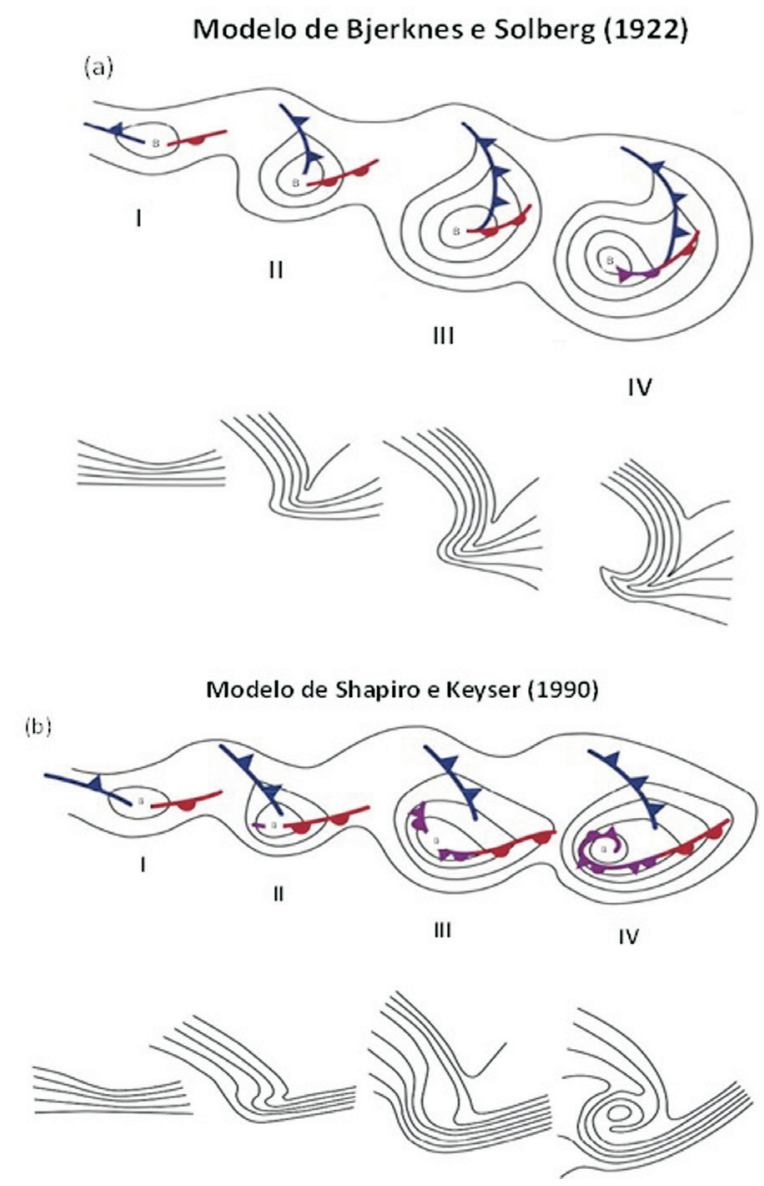

Figura 5 - Modelos conceituais do ciclo de vida dos ciclones extratropicais no Hemisfério Sul: a) modelo de Bjerknes e Solberg (1922) e b) modelo de Shapiro e Keyser (1990). O painel superior de cada modelo mostra a altura geopotencial em $850 \mathrm{hPa}$ e as frentes fria (azul), quente (vermelha) e oclusa (roxa). Já o painel inferior apresenta a temperatura potencial também em $850 \mathrm{hPa}$. Os estágios de vida representam intervalos de 6 a 24 horas. Adaptado de Schultz et al. (1998). Ver texto para maiores detalhes.

inicial da oclusão. Já a Fig. 5a suprime o estágio do ciclo de vida do ciclone com essa característica. Isso é um fato que ocorre na maioria das figuras ilustrativas do modelo de Bjerknes e Solberg em livros-textos. Voltando a comparação dos dois modelos conceituais de ciclone extratropical, no ciclone tipo Bjerknes e Solberg a seclusão de ar quente ocorre no período inicial da oclusão e depois tende a desaparecer, enquanto que no de Shapiro e Keyser, a seclusão de ar quente é uma característica dominante na fase final do ciclone. Em ambos os modelos conceituais (Fig. 5), nota-se que o raio dos ciclones extratropicais aumenta ao longo do ciclo de vida desses. De acordo com Rudeva e Gulev (2007), o raio dos ciclones é mais extenso quanto maior for sua duração em dias. À medida que um ciclone se forma, a convergência em superfície também aumenta fortalecendo o sistema. Com a expansão vertical do sistema, o raio vai aumentando. Uma forma de mostrar essa relação é através do raio de deformação de Rossby $\left(L_{R}\right)$ que para sistemas de tempo com grande vorticidade relativa pode ser generali- 
zado como: $L_{R}=N H /\left(\zeta+f_{o}\right)$, onde $N$ é a frequência de Brunt Väisäla, $H$ é a profundidade do sistema, $\zeta$ é a componente vertical da vorticidade relativa e $f_{o}$ é o parâmetro de Coriolis. À medida que $H$ aumenta, $L_{R}$ também aumenta.

De acordo com Schultz et al. (1998) e Schultz e Wernli (2001), os ciclones embebidos num escoamento difluente em altos níveis tendem a evoluir de acordo com o modelo de Bjerknes e Solberg, enquanto os embebidos num escoamento confluente tendem a evoluir de acordo com o modelo de Shapiro e Keyser.

Embora grande parte das ciclogêneses ocorra associada aos processos descritos nos modelos conceituais, ainda existem outras forçantes que podem influenciar de forma positiva ou negativa os ciclones, como: topografia, fontes diabáticas de calor e interação troposfera-estratosfera, porém essas não serão abordadas aqui. Para uma revisão dessas forçantes nas ciclogêneses ocorridas no sudoeste do oceano Atlântico Sul, próximo à costa leste da América do Sul, o leitor pode consultar Reboita et al. (2012) e os estudos de caso usando modelo numérico em Piva et al. (2008, 2011).

\subsubsection{Nebulosidade dos ciclones extratropicais em imagens de satélite}

Os ciclones extratropicais também podem ser chamados de ciclones de latitudes médias ou de ciclones frontais, e apresentam comprimento de onda que pode variar de 1500 a $5000 \mathrm{~km}$ e tempo de vida médio de 3 dias (Simmonds e Keay, 2000a; Reboita et al., 2010). Esses sistemas extratropicais são foco de muitos estudos, uma vez que causam tempo adverso, como ventos fortes, mudanças na temperatura do ar, nebulosidade e precipitação.

Em termos de nebulosidade, um modelo conceitual baseado na análise de imagens de satélite foi apresentado por Troup e Streten (1972) para os ciclones extratropicais no Hemisfério Sul. Neste modelo, as nuvens associadas com os ciclones podem apresentar cinco estágios (Fig. 6): W que indica estágio de onda, A estágio de formação, B estágio de formação avançado, $\mathrm{C}$ estágio de maturidade e Dx e Dy para o estágio de dissipação. O estágio C mostra que na maturidade dos ciclones (fase de oclusão), as nuvens apresentam um padrão espiralado. Entretanto, destaca-se que nas cartas sinóticas de superfície o traçado das frentes associadas com os ciclones nunca terá essa forma de espiral. Para tal observação, basta comparar as Figs. 5 e 6.

Muitos dos ciclones extratropicais que se formam próximos à costa leste da América do Sul se diferenciam ligeiramente do modelo de Troup e Streten (1972) por não apresentarem o estágio W. Isto ocorre quando as ciclogêneses são iniciadas por influência de cavados ou vórtices ciclônicos de altos níveis que cruzam os Andes em direção ao oceano Atlântico Sul. Assim, a banda de nuvens se desenvolve corrente abaixo do eixo do cavado ou do vórtice sem apresentar o estágio inicial de onda (estágio W).
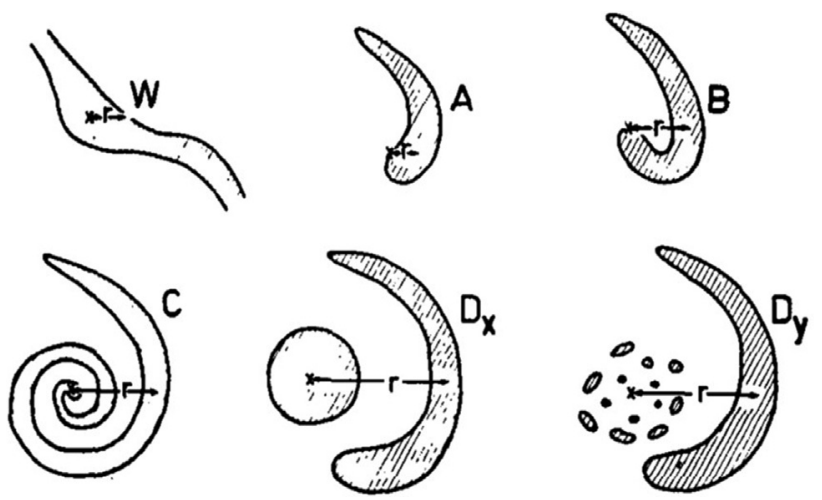

Figura 6 - Ilustração esquemática do padrão de nuvens associado com ciclones extratropicais no Hemisfério Sul. X indica o ponto considerado como centro do vórtice e $\mathrm{r}$ a distância considerada como raio. As letras nas imagens indicam o estágio do ciclo de vida do ciclone (ver definições no texto). Adaptado de Troup e Sreten (1972).

O artigo parte II apresentará uma análise sinótica de dois ciclones extratropicais: um que segue o modelo de Bjerknes e Solberg (1922) e outro o de Shapiro e Keyser (1990) e se relacionará o padrão da nebulosidade com o modelo de Troup e Streten (1972).

\subsection{Ciclones tropicais}

\subsubsection{Ciclo de vida dos ciclones tropicais}

Os ciclones tropicais são sistemas de baixa pressão não-frontal, com núcleo quente, que se desenvolvem sobre os oceanos tropicais ou subtropicais e possuem circulação em superfície bem organizada (Gray, 1968; Frank, 1977). Os ciclones tropicais possuem diâmetro $(500-1000 \mathrm{~km})$ menor do que os extratropicais e são mais intensos, simétricos e duradouros. Outra diferença é em relação a localização dos ventos mais intensos: enquanto nos ciclones extratropicais os ventos mais intensos ocorrem perto da tropopausa, nos ciclones tropicais eles ocorrem nos baixos níveis da troposfera.

O National Hurricane Center (NHC, s/d) faz uma classificação do tipo de ciclone tropical com base na intensidade dos ventos máximos sustentados. Segundo essa classificação, quando o ciclone apresenta ventos sustentados de até $61 \mathrm{~km} \mathrm{~h}^{-1}$ é denominado de depressão tropical, quando a intensidade varia entre 62 e $118 \mathrm{~km} \mathrm{~h}^{-1}$, o sistema é chamado de tempestade tropical e quando atinge intensidade maior ou igual a $119 \mathrm{~km} \mathrm{~h}^{-1}$ é chamado de furacão na bacia do Atlântico Norte e Pacífico Leste (de tufão no Pacífico Oeste e apenas de ciclone no Índico e cercanias da Austrália, mas tal nomenclatura não é dada pelo NHC). Além disso, há a categoria de furacão severo quando os ventos sustentados máximos atingem $178 \mathrm{~km} \mathrm{~h}^{-1}$. Portanto, o ciclo de vida de um ciclone tropical pode iniciar na fase de depressão tropical e evoluir para furacão (se for considerada a bacia do Atlântico Norte, por exemplo). Para os ciclones tropicais que atingem o estágio de furacão, existe ainda uma classificação, a de Saffir-Simpon, que relaciona a intensidade 
dos ventos sustentados com os danos causados por esses sistemas. A categoria 1 é aquela em que os ventos sustentados são entre 119-153 $\mathrm{km} \mathrm{h}^{-1}$, podendo causar danos em telhados, quedas de partes de árvores etc. Os ventos aumentam na categoria 2 para $154-177 \mathrm{~km} \mathrm{~h}^{-1}$, na categoria 3 para $178-208 \mathrm{~km} \mathrm{~h}^{-1}$, na categoria 4 para $209-251 \mathrm{~km} \mathrm{~h}^{-1} \mathrm{e}$ na categoria 5 para mais intensos do que $252 \mathrm{~km} \mathrm{~h}^{-1}$. Nessa última categoria os danos são grandes com destruição das áreas construídas, quedas de árvores etc. Em geral, a área afetada pelos ciclones com categoria 5 ficam inabitadas por semanas ou meses em virtude dos estragos.

Gray (1968) identificou seis características ambientais necessárias, mas não suficientes, para a gênese dos ciclones tropicais no globo: (1) temperatura da superfície do mar (TSM) excedendo a $26,5^{\circ} \mathrm{C}$, (2) valores elevados de umidade relativa na média troposfera $(700 \mathrm{hPa}),(3)$ instabilidade condicional, (4) distúrbio ciclônico em baixos níveis, (5) fraco cisalhamento vertical do vento horizontal e (6) local da gênese distante do equador em cerca de $5^{\circ}$ a $6^{\circ}$.

A gênese dos ciclones tropicais com base nas características descritas por Gray (1968) pode ser pensada da seguinte forma: perturbações nos níveis atmosféricos acima da superfície, a cerca de 1 a $2 \mathrm{~km}$ de altura (como as ondas de leste), podem causar distúrbios ciclônicos em baixos níveis (4). Esses distúrbios podem favorecer a convergência dos ventos em superfície que intensificam os fluxos turbulentos de calor latente e sensível do oceano para a atmosfera (teoria Wind-Induced Surface Heat Exchange - WISHE; Emanuel 1986, 1991), o que indica a importância de TSM's elevadas (1) para o aumento da umidade relativa na média troposfera (2). Nesse processo, a instabilidade condicional (3) torna-se importante, pois o calor latente liberado na condensação aquecerá as parcelas de ar que poderão continuar a ascender na atmosfera, contribuindo para a redução da pressão nos níveis mais baixos e, consequentemente, aumento da convergência de massa e o movimento vertical ascendente. Para a convecção profunda se manter é necessário um fraco cisalhamento vertical do vento horizontal (5; Gray, 1968; Mundell, 1990; DeMaria et al., 2001), pois o forte cisalhamento vertical do vento transporta o calor para longe do local de desenvolvimento do distúrbio (Fig. 7). Além disso, a liberação de calor por condensação pelos cumuli na alta troposfera é advectada para uma direção diferente da liberação de calor latente em níveis mais baixos. Isso torna mais difícil a concentração de calor por toda a troposfera. Gray (1968) menciona que no sudoeste do oceano Atlântico Sul a gênese de ciclones tropicais é prejudicada devido ao forte cisalhamento vertical do vento que existe entre os níveis de 200 e $850 \mathrm{hPa}$, o qual é de cerca de 10 a $20 \mathrm{~m} \mathrm{~s}^{-1}$. Já para uma região próxima à costa sul do Brasil e considerando a mesma camada vertical, Pezza e Simmonds (2005) encontraram valores ainda maiores $\left(\sim 26 \mathrm{~m} \mathrm{~s}^{-1}\right)$. Por fim, como a força de Coriolis é importante para iniciar a rotação dos sistemas, os ciclones tropicais devem se formar afastados do equador (6), onde a força de Coriolis não será nula.

Com relação ao cisalhamento vertical do vento, a Fig. 7 mostra uma ilustração esquemática adaptada de Mundell (1990) para facilitar o entendimento desse na gênese de ciclones tropicais. Na figura, a parte (a) mostra as condições favoráveis à gênese, enquanto a parte (b) as condições desfavoráveis. De acordo com Mundell (1990), para a intensificação dos ciclones tropicais é necessário fraco cisalhamento vertical do vento por toda a troposfera, pois isso permite o alinhamento vertical do ciclone tropical de modo que facilite o transporte de movimento ciclônico para níveis mais altos (e a vorticidade ciclônica torna-se mais eficiente em altos níveis, pois reduz a área da circulação comparada à superfície) e resulta em queda mais eficiente da pressão na superfície no centro do sistema devido ao aquecimento em altos níveis. Em decorrência desses fatores, há uma circulação ciclônica extensa verticalmente (o que também pode se chamar de sistema profundo).

De acordo com a Fig. 7a, a área da circulação ciclônica é maior em baixos níveis da atmosfera e menor em altos níveis, o que favorece a vorticidade se tornar mais intensa em altos níveis (efeito bailarina). Segundo Mundell (1990), nessa situação há mais possibilidade de ocorrer convergência em baixos níveis e concentração de convecção cumuli profundos. Também são observados na Fig. 7a maiores desvios horizontais de temperatura na região central do ciclone na alta troposfera do que na baixa troposfera (Fig. 7a central). Essa informação parece contraditória, uma vez que é a existência de camadas mais quentes na baixa do que na alta atmosfera que a instabiliza. Entretanto, estudos de caso de ciclones tropicais (Hawkins and Rubsam, 1968; Emanuel, 1998; Kidder et al., 2000; Reboita et al., 2016, parte II) mostram que o aquecimento no núcleo desses sistemas é mais intenso no topo da tempestade favorecendo desvios zonais mais intensos. Já, próximo da superfície, os desvios podem ser até negativos. Um exemplo é mostrado no caso do ciclone tropical Hilda ocorrido em $1^{\circ}$ de outubro de 1964 (Fig. 7c). O maior aquecimento da alta troposfera pode estar relacionado com o aquecimento por liberação de calor latente de condensação associado à convecção profunda existente no ciclone (Kidder et al., 2000). Já os fracos desvios zonais de temperatura do ar ou mesmo negativos podem ser devido aos ventos fortes que propiciam a ocorrência da evaporação tanto do spray oceânico quanto da própria precipitação. Estudos como o de Hawkins e Rubsam (1968), Hawkins e Imbembo (1976) e Kidder et al. (2000) mostram essa característica fria na base de alguns ciclones tropicais.

Outro fato que deve ser mencionado são os limiares de TSM para a ocorrência dos ciclones tropicais. Apesar de muitos estudos mostrarem que a formação dos ciclones tropicais ocorre quando a TSM for maior do que $26,5^{\circ} \mathrm{C}$ (Gray, 1968; Galvin, 2008), recentemente, Dare e McBride (2011) e McTaggart-Cowan et al. (2015) chamaram a aten- 

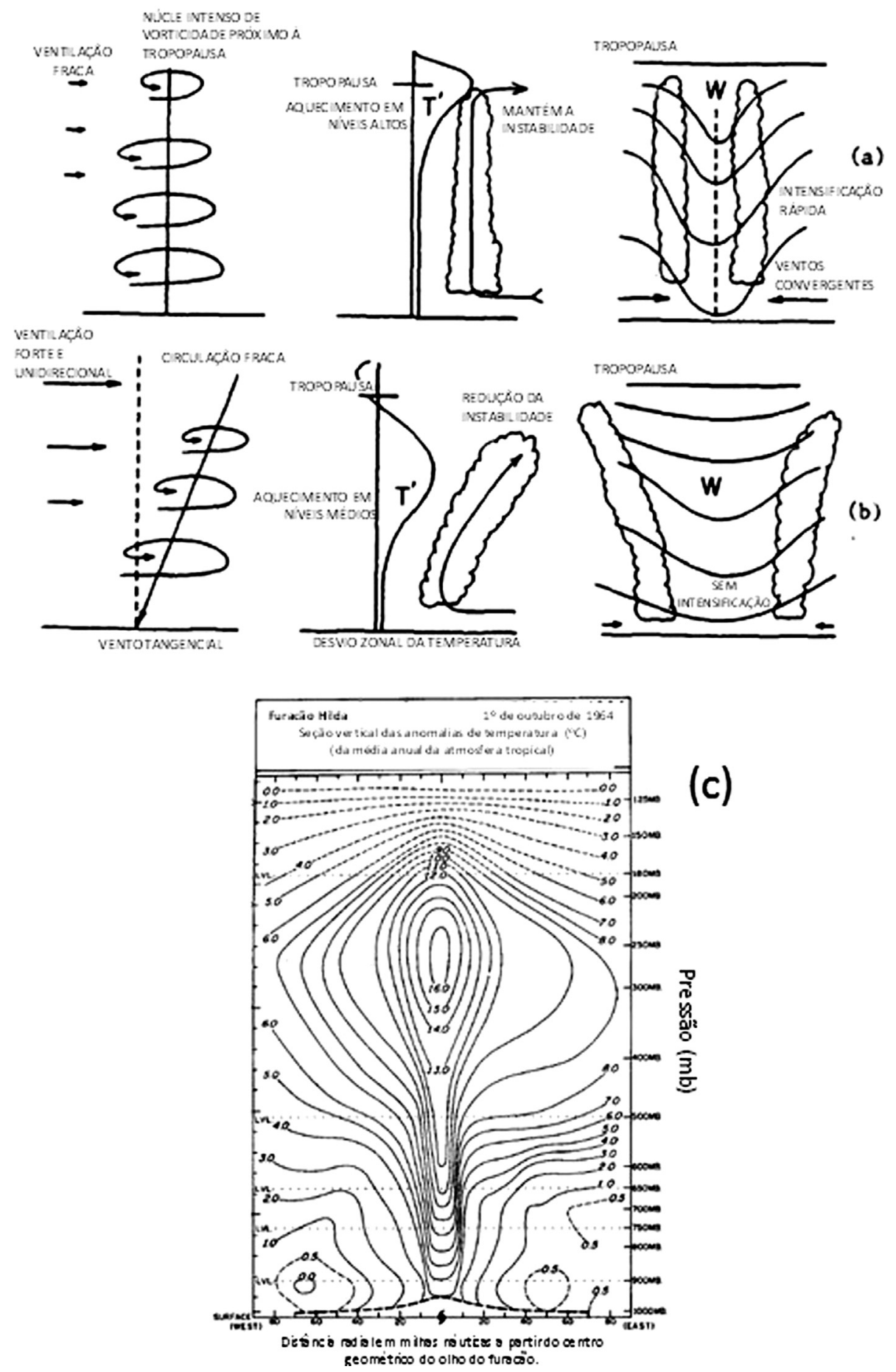

Figura 7 - Condições favoráveis (painel superior - a) e desfavoráveis (painel inferior - b) para a intensificação dos ciclones tropicais baseadas em Mundell (1990). Nas figuras, T' indica anomalia de temperatura e W que a região está mais aquecida em relação ao redor. No painel c, tem-se um exemplo de perfil vertical da anomalia zonal de temperatura do ar no ciclone tropical Hilda, que ocorreu em $1^{\circ}$ de outubro de 1964 (Hawkins and Rubsam, 1968). O uso das palavras desvio e anomalia distingue-se pelo fato de que anomalia corresponde a uma diferença em relação à média temporal, enquanto desvio pode ser uma diferença apenas em relação a uma média de dados latitudinais num dado tempo.

ção para ocorrência de ciclones tropicais sobre águas com temperaturas inferiores a $26,5^{\circ} \mathrm{C}$; sendo que Dare e McBride (2011) encontram um total de 7\% dos ciclones tropicais com essa característica numa climatologia entre $35^{\circ} \mathrm{S}$ e $35^{\circ} \mathrm{N}$ no período de 1981 a 2008.
A expressão "necessária, mas não suficiente" mencionada anteriormente significa que todas as seis características ambientais devem ocorrer simultaneamente para se ter a gênese de um ciclone tropical, entretanto, mesmo na presença dessas características, a ciclogênese tropical pode 
não ocorrer. De acordo com o COMET (s/d), para ocorrer a ciclogênese tropical é necessário que a atmosfera mantenha a convecção profunda na presença de vorticidade absoluta ciclônica em baixos níveis. A habilidade da convecção de se manter por vários dias depende da sua vorticidade, estabilidade e profundidade. Esses três fatores estão inseridos na definição do raio de deformação de Rossby $\left(L_{R}\right)$. O $L_{R}$ é uma escala de comprimento crítica em que a rotação de um sistema torna-se tão importante quanto a flutuação (Gill, 1982). Quando o comprimento horizontal do distúrbio é maior (menor) do que $L_{R}$, ele persiste (desaparece).

Assim como existe um processo de gênese dos ciclones tropicais, também existe a ciclólise desses sistemas. As principais causas que podem provocar a ciclólise estão relacionadas ao desaparecimento de uma ou mais condições que favorecem a ciclogênese. Por exemplo, um ciclone que se desloca sobre regiões com TSMs mais frias perde a capacidade de sustentar convecção profunda, devido à redução dos fluxos de calor em superfície; a presença de intenso cisalhamento vertical do vento pode desorganizar o sistema, pois transporta calor e umidade para longe do local do distúrbio. As áreas continentais também são fonte de dissipação dos ciclones tropicais, uma vez que não fornecem a energia necessária para manter os ciclones (a umidade) e devido à rugosidade da superfície, acabam desorganizando o ciclone tropical, que sobre o oceano é bastante simétrico. Os ciclones tropicais também podem deixar de existir após a transição para um ciclone extratropical (Jones et al., 2003). À medida que um ciclone tropical se move em direção ao polo, a baroclinia do ambiente aumenta e pode ocorrer interações com outras características sinóticas (como frentes, cavados em altos níveis, ciclones extratropicais). A interação entre os sistemas de origem tropical e extratropical podem favorecer a transição. Entretanto, fatores que são favoráveis na transição de um sistema podem não ser em outro, como salienta Jones et al. (2003).

Com relação à estrutura vertical dos ciclones tropicais (Fig. 8), esses sistemas apresentam: (A) escoamento convergente na camada limite atmosférica, (B) parede do olho que é uma camada de nuvens extensa verticalmente, (C) nuvens em forma espiraladas, (D) regiões com movimentos subsidentes entre as bandas de nuvens e (E) escoamento divergente na alta troposfera e bandas de cirrus. Quando um ciclone tropical atinge a categoria de furacão, ele apresenta no seu centro um olho, em que há movimentos subsidentes e ausência de nebulosidade (F).

\subsubsection{Nebulosidade dos ciclones tropicais em imagens de satélite}

O padrão de nuvens num ciclone tropical na categoria de furacão no Hemisfério Sul é indicado na Fig. 9. O círculo concêntrico de nuvens ao redor do olho do sistema corresponde à parede do olho, mais afastadas desse encontram-se as bandas espiraladas de nuvens que também são denominadas de bandas de chuva.

Embora o foco do presente estudo seja o Hemisfério Sul, uma figura da evolução temporal entre os dias 19 e 21 de outubro de 2005 do furacão Wilma (Fig. 10), ocorrido na bacia do oceano Atlântico Norte Tropical, é mostrada para ilustrar tanto o padrão da nebulosidade do ciclone no canal visível do satélite GOES-12 quanto a temperatura de brilho no plano e em perfil vertical. Essa última característica mostra claramente a estrutura vertical do ciclone confirmando o modelo conceitual da Fig. 8. Com os produtos de satélite, é possível mostrar que a parede do olho do furacão pode ter máxima intensidade da atividade convectiva e quando essa enfraquece há a intensificação de uma banda de nebulosidade circundando o olho ligeiramente mais afastada. Na primeira coluna da Fig. 10, dia 19 de outubro de 2005 , é mostrado um pequeno olho no furacão. Na

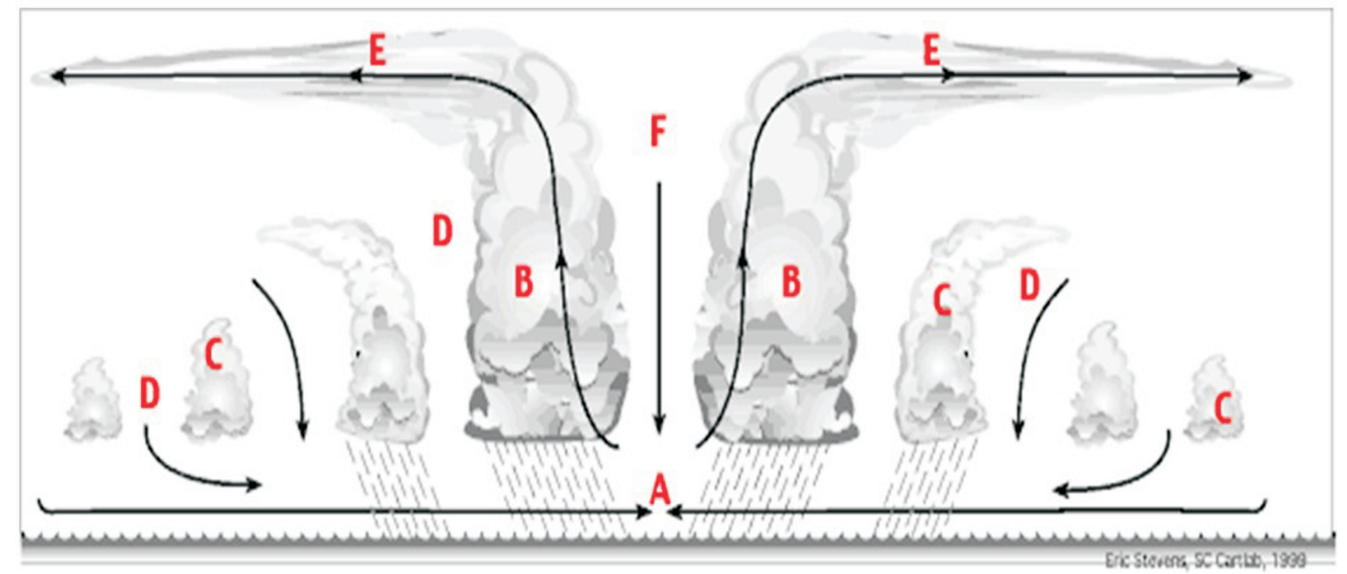

Figura 8 - Estrutura vertical de um ciclone tropical na categoria de furacão, onde: A indica região de convergência em superfície, B é a parede do olho, C são as bandas de nuvens espiraladas, D são regiões de fraca convecção e/ou movimentos subsidentes, E indica o movimento divergente na alta troposfera e bandas de cirrus e F representa o movimento subsidente no olho do sistema. Adaptado de http://people.cas.sc.edu/carbone/modules/mods4car/tropcycl/pages/structure.html. 


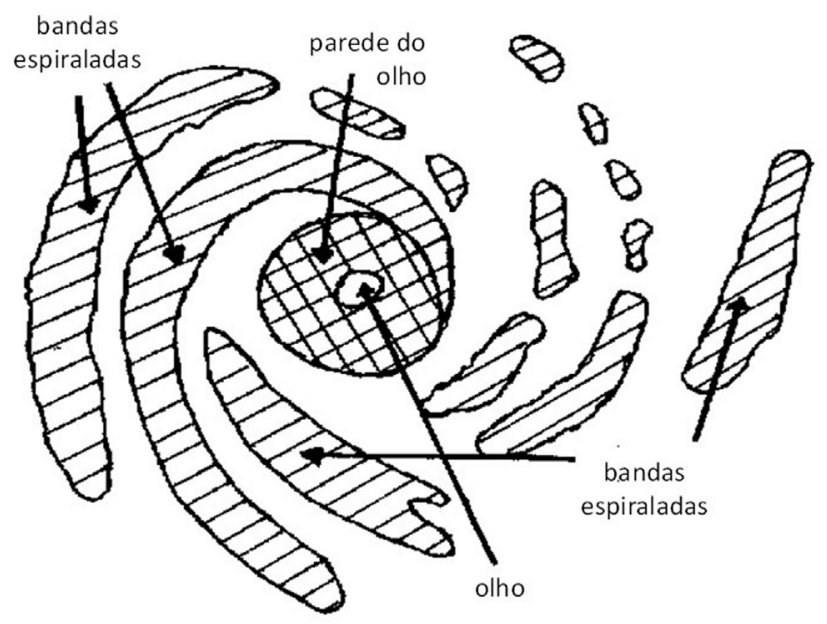

Figura 9 - Ilustração esquemática da nebulosidade nos ciclones tropicais na categoria de furacão no Hemisfério Sul baseada em imagens de satélite. Adaptado de http://www.oas.org/cdmp/document/forecast/forecast.htm.

segunda coluna, dia 20 de outubro, o brilho da banda de nuvens ao redor do olho do sistema é bem mais intenso do que no dia 19. Já na terceira coluna, nota-se que há um enfraquecimento da atividade convectiva que forma a parede do olho do furacão e intensificação de uma nova parede ligeiramente mais afastada.

\subsection{Ciclones subtropicais}

\subsubsection{Ciclo de vida dos ciclones subtropicais}

Os ciclones subtropicais, também chamados de sistemas híbridos, são centros de baixa pressão que apresentam núcleo quente em baixos níveis da atmosfera, como os ciclones tropicais, e frio em altos níveis, como os ciclones extratropicais (Hart, 2003). Um ciclone pode ter gênese como subtropical ou sofrer transição de extratropical ou de tropical para subtropical. Esses sistemas híbridos ocorrem em diferentes lugares do globo como no mar Mediterrâneo onde são chamados de Medicanes (Fita et al., 2007; Cavicchia et al., 2014), próximo da Austrália (Holland et al., 1987; Garde et al., 2009), na bacia do Atlântico Norte (Evans e Guishard, 2009; Guishard et al., 2009) e na bacia do Atlântico Sul (Evans e Braun, 2012; Dutra, 2012; Mathias, 2012; Reboita et al., 2013; Dias Pinto et al., 2013; Gozzo et al., 2014). Enquanto na bacia do Atlântico Norte, os estudos de Evans e Guishard (2009) e Guishard et al. (2009) indicam uma frequência de quatro sistemas por ano, na bacia do Atlântico Sul, Evans e Braun (2012) encontraram uma frequência de 1,2 sistemas por ano. Já Gozzo et al. (2014), utilizando dados da reanálise do NCEP e do ECMWF, obtiveram uma frequência de $\sim 7,2$ sistemas por ano. O maior número médio anual de ciclones subtropicais encontrados por Gozzo et al. (2014) deve-se ao fato de que esses autores usaram limiares menos rígidos para a clima-
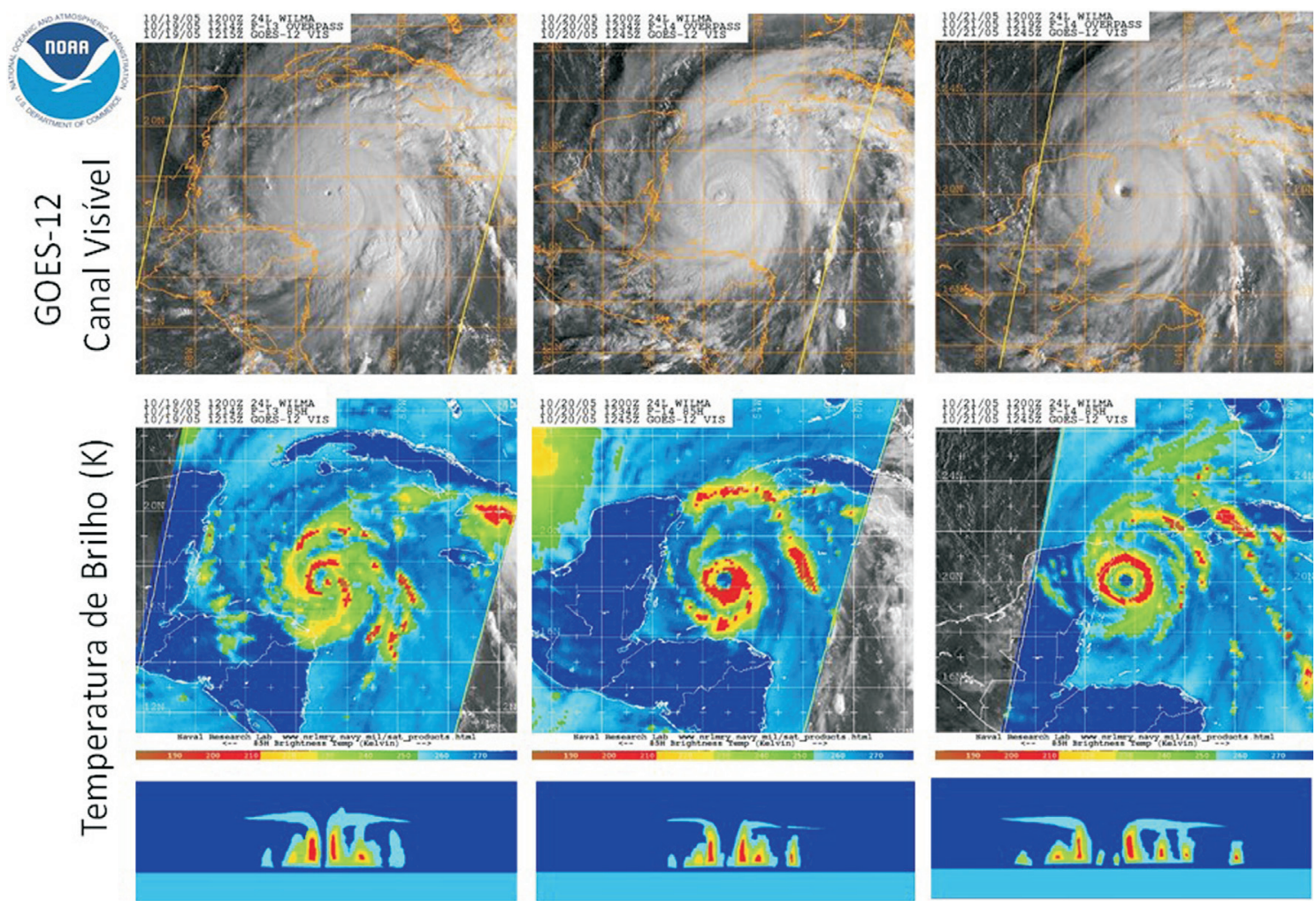

Figura 10 - Evolução do furacão Wilma entre os dias 19 e 21 de outubro de 2005 (colunas). Na figura a primeira linha corresponde às imagens do satélite GOES-12 no canal visível, a segunda linha a temperatura de brilho (K) e a terceira linha, um perfil vertical da temperatura de brilho. Adaptado de Stan Goldenberg http://www.aoml.noaa.gov/hrd/tcfaq/D8.html. 


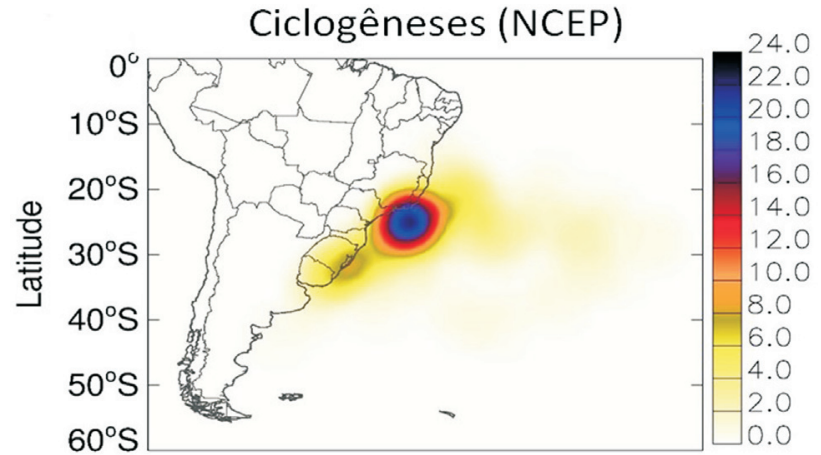

Figura 11 - Densidade (número de ciclones por radiano quadrado por dia, em outras palavras, para o resultado ser em $\mathrm{km}$, converte-se a unidade radiano para graus e depois para $\mathrm{km}$ ) de ciclogêneses subtropical obtida da reanálise 1 do NCEP. Adaptada de Gozzo et al. (2014).

tologia, como: inclusão de sistemas que não apresentavam baixa fechada na média troposfera e/ou cujo vento máximo em $925 \mathrm{hPa}$ não atingia $17 \mathrm{~m} \mathrm{~s}^{-1}$. Entretanto, Evans e Braun (2012) e Gozzo et al. (2014) mostraram a região oceânica próxima da costa sul/sudeste do Brasil como a de maior ocorrência desses sistemas (Fig. 11). Com relação à variabilidade sazonal, os ciclones subtropicais no sudoeste do oceano Atlântico Sul ocorrem preferencialmente no verão. Outras características encontradas por Gozzo et al. (2014) são que os ciclones subtropicais percorrem distâncias menores do que os extratropicais, e com menor velocidade.

Embora a atenção aos ciclones subtropicais só tenha aumentado com os trabalhos de Hart (2003), Evans e Guishard (2009) e Guishard et al. (2009), na década de 1960 já se usava na literatura o termo ciclone subtropical. Gray (1968), em seu estudo sobre os ciclones tropicais, dedicou uma seção para os subtropicais onde mencionou que tempestades do tipo híbridas, com características de ambos ciclones tropical e extratropical, ocorriam em latitudes entre $25^{\circ}$ e $35^{\circ} \mathrm{S}$ e na área mais a noroeste dessa banda de latitude nos oceanos Atlântico e Pacífico. Gray (1968) também mencionou que os ciclones subtropicais não possuem intenso núcleo convectivo e que os ventos máximos ocorrem afastados do seu centro.

De maneira geral, os estudos indicam que os ciclones subtropicais se formam associados à presença de um cavado ou de um VCAN (cutoff low) em altos níveis da atmosfera (exemplo: Holland et al., 1987; Evans e Braun, 2012; Dias Pinto et al., 2013; Gozzo et al., 2014) e na presença de uma perturbação ciclônica em superfície, ou seja, num

\section{Hemisfério Sul}

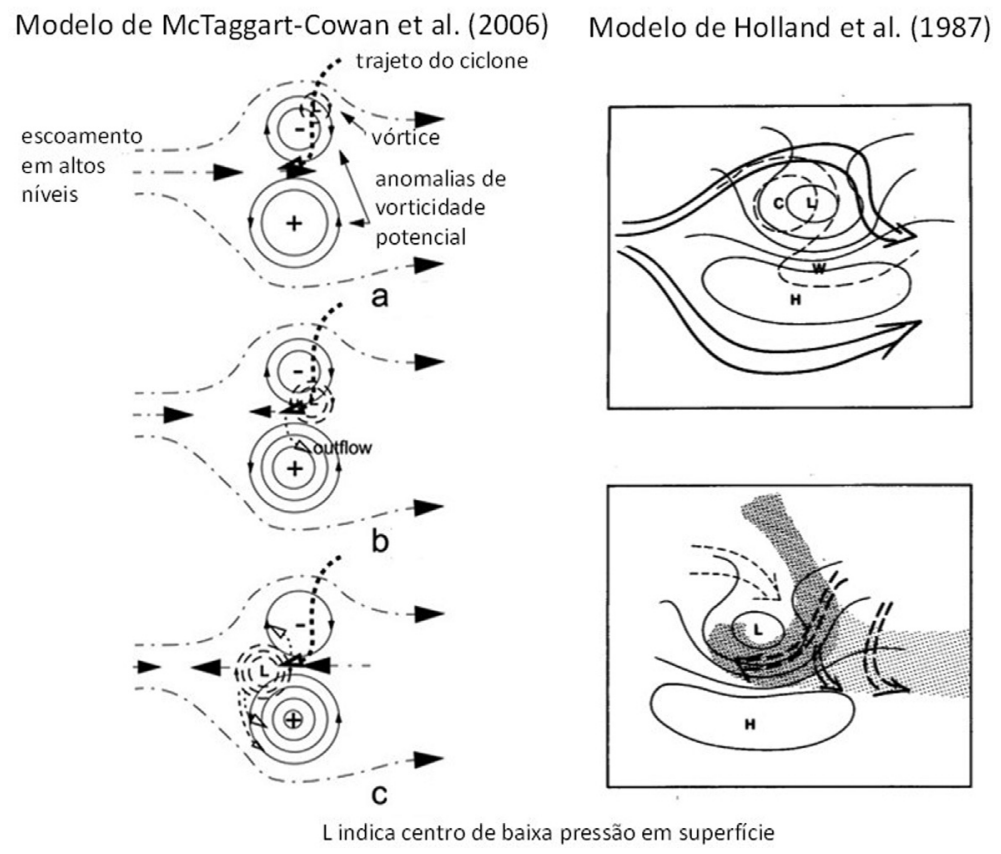

Figura 12 - Lado esquerdo: modelo conceitual adaptado de McTaggart-Cowan et al. (2006) em que em altos níveis da atmosfera há um bloqueio do tipo dipolo no Hemisfério Sul. A direção do escoamento em altos níveis é representada por linhas tracejadas e pontilhadas; a trajetória do ciclone (L) em superfície é destacada em (a) com linha tracejada em negrito. Na figura (b), o ciclone em superfície se encontra entre a interface de duas circulações com sentidos opostos o que reduz a intensidade do escoamento de oeste em altos níveis e favorece o deslocamento do ciclone para oeste (c). Lado direito: modelo conceitual adaptado de Holland et al. (1987) para o Hemisfério Sul. No painel superior são mostradas as isóbaras em superfície (linhas contínuas), a espessura da camada 100/500 hPa (linhas tracejadas) e os jatos em altos níveis (linhas pretas em negrito). No painel inferior são apresentadas as isóbaras em superfície (linhas contínuas), as nuvens estratiformes em área com convecção (área hachurada mais densa) e com pouca convecção (área hachurada menos densa) e trajetória das isentrópicas de temperatura potencial de bulbo úmido com movimento subsidente ao longo da seta tracejada (noroeste do modelo) e movimento ascendente ao longo das demais setas. As letras L e H indicam, respectivamente, regiões com baixa e alta pressão em superfície, já as letras $\mathrm{C}$ e $\mathrm{W}$ indicam, respectivamente, região fria e região quente. 
ambiente baroclínico (Guishard, 2006); mas seu desenvolvimento só ocorre se a convecção puder ser mantida. É interessante ressaltar que o núcleo quente dos ciclones subtropicais é bem mais raso do que dos tropicais (não ultrapassando os $500 \mathrm{hPa}$ ), impedindo que o sistema seja mantido apenas pelo mecanismo de feedback entre a circulação e os fluxos de calor do oceano (Guishard et al., 2009). Assim, torna-se importante a componente dinâmica dos cavados ou dos VCANs, isto é, a divergência que ocorre a leste contribui para movimentos verticais ascendentes. Isso é um mecanismo que está associado à intensificação dos ciclones extratropicais e cisalhamento vertical do vento, o que atuaria de maneira negativa para a organização da convecção no núcleo do sistema subtropical. Entretanto, em vários casos de ciclones subtropicais nota-se que o VCAN faz parte de um bloqueio do tipo dipolo, ou seja, há uma crista ou uma alta no lado polar do VCAN (Fig. 12). Assim, os ventos de oeste em latitudes subtropicais acabam enfraquecendo na interfase do VCAN e da crista e até podem mudar de sentido. Portanto, esse ambiente favorece a redução do cisalhamento vertical do vento, de modo que a conveç̧ão pode ser sustentada. Os modelos conceituais apresentados em Holland et al. (1987) e McTaggart-Cowan et al. (2006), reproduzidos na Fig. 12, ilustram os mecanismos físicos descritos anteriormente.

Gozzo et al. (2014), através da análise de composições, mostraram que entre as principais características associadas aos ciclones subtropicais no sudoeste do oceano Atlântico Sul tem-se a presença de um padrão de bloqueio do tipo dipolo. Esse padrão também foi documentado no estudo de caso do ciclone subtropical Anita (Dutra, 2012; Dias Pinto et al., 2013). Ainda com relação ao Anita, Dias Pinto et al. (2013) mostraram que o seu ciclo de vida foi marcado por uma transição extratropical, devido ao enfraquecimento dos fluxos de calor latente e à interação do ciclone com um distúrbio extratropical situado a sudoeste. Ao longo do ciclo de vida, o Anita se deslocou para sudoeste quando se acoplou a um padrão similar a bloqueio do tipo dipolo em altos níveis e adquiriu estrutura vertical barotrópica. Após a ocorrência do ciclone Anita, o caso seguinte de ciclogênese subtropical no sudoeste do oceano Atlântico Sul de repercussão na comunidade científica foi o sistema denominado de Arani (Mathias, 2012). Esse sistema se desenvolveu associado a umfraco cavado em $500 \mathrm{hPa}$ (sem assinatura em $300 \mathrm{hPa}$ ) como será mostrado no estudo de caso (artigo parte II).

Com relação à nebulosidade dos ciclones subtropicais, ainda não há estudos que sintetizem os principais padrões das nuvens em imagens de satélite.

\section{Conclusões}

Este trabalho teve como objetivo compilar informações da literatura sobre as características sinóticas de quatro tipos de ciclones em latitudes austrais: extratropical seguindo o modelo conceitual de Bjerknes e Solberg, extra-

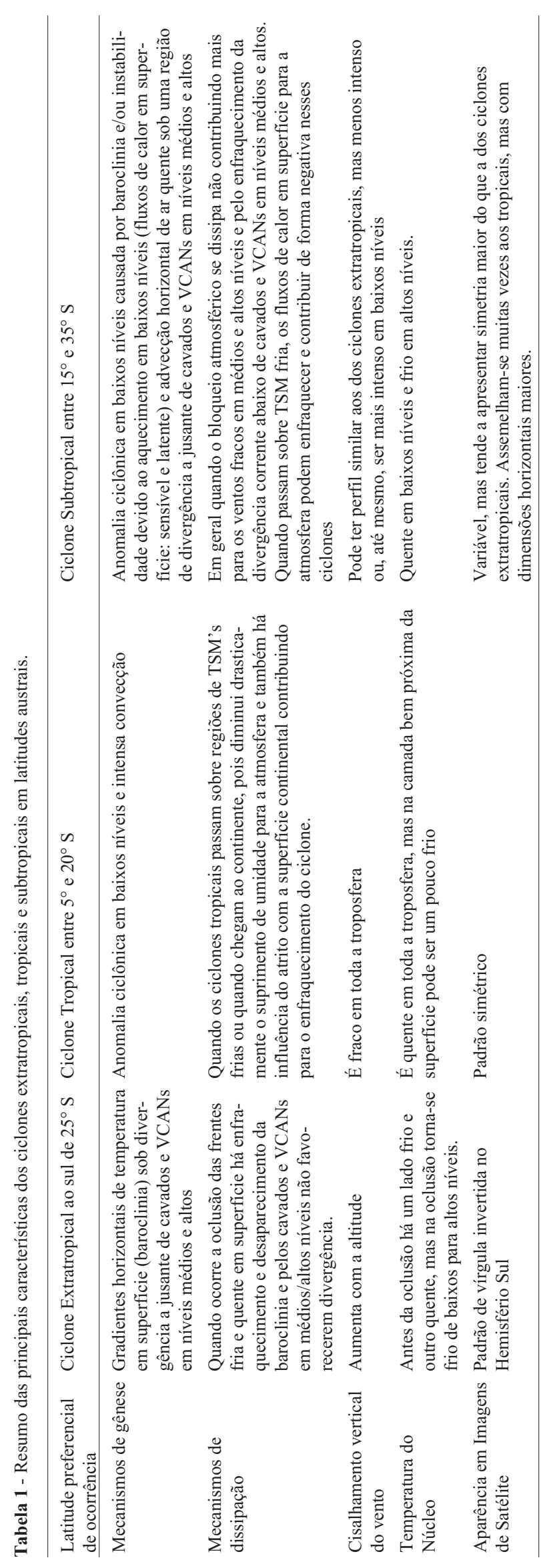


tropical seguindo o modelo de Shapiro e Keyser, tropical e subtropical. As informações apresentadas aqui mostram que os modelos conceituais são importantes para ajudar na compreensão dos sistemas, mas isso não significa que todos os casos de ciclones se igualam perfeitamente aos modelos conceituais.

Quanto aos ciclones extratropicais seguindo o modelo de Bjerknes e Solberg e de Shapiro e Keyser, esses se diferenciam principalmente pela trajetória da frente fria, que não gira ao redor do centro do ciclone e, sim, segue quase perpendicular à frente quente no modelo de Shapiro e Keyser. Como as diferenças entre os dois tipos de ciclones extratropicais são sutis, devem ser abordadas nas disciplinas de laboratório de meteorologia sinótica e previsão de tempo. Um pequeno resumo das principais características dos ciclones extratropicais (sem diferenciar os modelos mencionados), tropicais e subtropicais é apresentado na Tabela 1.

\section{Agradecimentos}

Os autores agradecem ao CNPq, CAPES e FAPESP (projeto SANSAO) pelo apoio financeiro.

\section{Referências}

BJERKNES, J. On the structure of moving cyclones. Geofysiske Publikasjoner, v. 1, n. 2, p. 1-8, 1919.

BJERKNES, J.; PALMÉN, E. Investigation of selected European cyclones by means of serial ascents. Geofysiske Publikasjoner, vol. 12, n. 2, p. 1-62, 1937.

BJERKNES, J.; SOLBERG, H. Life cycle of cyclones and the polar front theory of atmospheric circulation. Geofysiske Publikasjoner, v. 3, p. 3-18, 1922.

BJERKNES, J.; HOLMBOE, J. On the Theory of Cyclones. Journal of Meteorology, v.1, p. 1-22, 1944.

BUZZI, A.; TIBALDI, S. Cyclogenesis in the lee of the Alps: A case study. Quarterly Journal of the Royal Meteorological Society, v. 104, p. 271-287, 1978.

BUZZI, A.; SPERANZA, A.; TIBALDI, S.; TOSI, E. A unified theory of orographic influences upon cyclogenesis. Meteorology and Atmospheric Physics, v. 36, p. 91-107, 1987.

CARLSON, T. Mid-Latitude Weather Systems. Harper Collins, New York, 512 pp, 1991.

CAVICCHIA, L.; VON STORCH, H.; GUALDI, S. A long-term climatology of medicanes. Climate Dynamics, v. 43:1183-1195, 2014.

CELEMÍN, A.H. Meteorologia Prática. Edición del Autor, Mar del Plata, República Argentina, 313 pp, 1984.

CHARNEY, J.G. The Dynamics of Long Waves in a Baroclinic Westerly Currents. Journal of Meteorology, p. 135-162, 1947.

COMET. Tropical Cyclones. In: Introduction to Tropical Meteorology. $2 \mathrm{a}$ ed. Disponível em http://www.meted.ucar.edu/tropical/textbook_2nd_edition/ navmenu.php?tab=9. Acesso em 11 de janeiro de 2015 .

DARE, R.A.; MCBRIDE, J.L. The threshold sea surface temperature condition for tropical cyclogenesis. Journal of Climate, v. 24, p. 4570-4576, 2011.
DEMARIA, M.; KNAFF, J.A.; CONNELL, B.H. tropical cyclone genesis parameter for the tropical Atlantic. Weather Forecasting, v. 16, p. 219-233, 2001.

DIAS PINTO, J.R.; DA ROCHA, R.P. The energy cycle and structural evolution of cyclones over southeastern South America in three case studies. Journal of Geophysical Research, v. 116, D14112, 2011.

DIAS PINTO, J R.; REBOITA, M.S.; DA ROCHA, R.P. Synoptic and dynamical analysis of subtropical cyclone Anita (2010) and its potential for tropical transition over the South Atlantic Ocean. Journal of Geophysical Research Atmosphere., v. 118, p. 10,870-10,883, 2013.

DUTRA, L.M.M. Ciclones Subtropicais sobre o Atlântico Sul: análise da estrutura dinâmica de eventos. 2012. Dissertação (Mestrado em Meteorologia). Instituto de Astronomia, Geofísica e Ciências Atmosféricas (IAG), Universidade de São Paulo, São Paulo, 136f.

EADY, E.T. Long Waves and Cyclones Waves. Tellus, v. 1, n. 3, p. 35-52, 1949.

EVANS J.L.; BRAUN, A. A Climatology of Subtropical Cyclones in the South Atlantic. Journal of Climate, v. 25, p. 7328-7340, 2012.

EVANS, J.L., GUISHARD, M.P. Atlantic Subtropical Storms. Part I: Diagnostic Criteria and Composite Analysis. Monthly Weather Review, v. 137, p. 2065-2080, 2009.

FITA, L.; ROMERO, R.; LUQUE, L.; EMANUEL, K.; RAMIS, C. Analysis of the environments of seven Mediterranean tropical-like storms using an axisymmetric, nonhydrostatic, cloud resolving model. Natural Hazards and Earth System Sciences Journal, v. 7, p. 41-56, 2007.

FRANK, W.M. The structure and energetics of the tropical cyclone I. Storm structure. Monthly Weather Review, v. 105, p. 1119-1135, 1977.

GALVIN, J.F.P. The weather and climate of the tropics: Part 7 Tropical revolving storms. Weather, v. 63, p. 327-333, 2008.

GAN, M.A.; RAO, V.B. Surface Cyclogenesis over South America. Monthly Weather Review, v. 119, p. 1293-1302, 1991.

GAN, M.A.; RAO, V.B. The Influence of the Andes Cordillera on Transient Disturbances. Monthly Weather Review, v. 122, n. 6, p. 1141-1157, 1994.

GAN, M.A.; Case Studies of Cyclogenesis over South America. Meteorological Applications, Inglaterra, v. 3, p. 359-368, 1996.

GARDE, L.A.; PEZZA, A.B.; BYE, J.A.T. Tropical transition of the 2001 Australian Duck. Monthly Weather Review, v. 138, p. 2038-2057, 2009.

GILL, A.E. Atmosphere-Ocean Dynamics. Academic Press, Orlando, $662 \mathrm{pp}, 1982$.

GOZZO, L.F.; DA ROCHA, R.P. Air-sea interaction processes influencing the development of a Shapiro-Keyser type cyclone over the subtropical South Atlantic Ocean. Pure and Applied Geophysics, v. 170, n. 5, p. 917-934, 2013.

GOZZO, L.F.; DA ROCHA, R.P.; REBOITA, M.S.; SUGAHARA, S. Subtropical Cyclones over the Southwestern South Atlantic: Climatological Aspects and Case Study. Journal of Climate, v. 27, p. 8543-8562, 2014.

GRAY, W.M. Global view of the origin of tropical disturbances and storms. Monthly Weather Review, v. 96, p. 669-700, 1968. 
GUISHARD, M.P.; EVANS, J.L.; HART, R. E. Atlantic Subtropical Storms. Part II: Climatology. Journal of Climate, v. 22, p. 3574-3594, 2009.

GUISHARD, M.P. Atlantic subtropical storms: Climatology and characteristics. 158 pp., $\mathrm{PhD}$ thesis, $\mathrm{Pa}$ State Univ., University Park, 2006.

HART, R.E. A cyclone phase space derived from thermal wind and thermal asymmetry. Monthly Weather Review, v. 131, p. 585-616, 2003.

HAWKINS, H.F.; RUBSAM, D.T. Hurricane Hilda, 1964 II. Structure and budgets of the hurricane on October 1, 1964. Monthly Weather Review, v. 96, p. 617-636, 1968.

HAWKINS, H.F.; IMBEMBO, S.M. The structure of a small, intense hurricane - Inez 1966. Monthly Weather Review, v. 104, p. 418-442, 1976.

HOLLAND, G.J.; LYNCH, A.H.; LESLIE, L.M. Australian East-Coast Cyclones. Part I: Synoptic Overview and Case Study. Monthly Weather Review, v. 115, p. 3024-3036, 1987.

HOSKINS, B.J.; HODGES, K.I. A New Perspective on Southern Hemisphere Storm Tracks. Journal of Climate, v. 18, p. 4108-4129, 2005.

IWABE, C.M.N.; DA ROCHA, R.P. An event of stratospheric air intrusion and its associated secondary surface cyclogenesis over the South Atlantic Ocean. Journal of Geophysical Research, v.114, p. 1-15, 2009.

JONES, S.C.; HAAR, P.A.; ABRAHAM, J.; BOSART, L.F. et al. The Extratropical Transition of Tropical Cyclones: Forecast Challenges, Current Understanding, and Future Directions. Weather and Forecasting, v. 18, p. 1052-1092, 2003.

KIDDER, S.Q., GOLDBERG, M.D.; ZEHR, R.M.; DEMARIA, M. et al. Satellite Analysis of Tropical Cyclones Using the Advanced Microwave Sounding Unit (AMSU). Bulletin of the American Meteorological Society, v. 81, n. 6, p. 1241-1259, 2000.

KNUTSON, T.R.; MCBRIDE, J.L; CHAN, J.; EMANUEL, K.; HOLLAND, G.; LANDSEA, C.; HELD, I.; KOSSIN, J.P.; SRIVASTAVA, A.K.; SUGI, M. Tropical cyclones and climate change. Nature Geoscience, v. 3, p. 157-163, 2010.

KOUSKY, V.E.; ELIAS, M. Meteorologia Sinótica: Parte I. São José dos Campos: INPE, 1982.

MATHIAS, R.S.B. Análise e classificação de ciclones utilizando diagramas de fase: conceitos e aplicação em previsão de tempo operacional. 2012. Dissertação de Mestrado em Meteorologia. Universidade Federal do Rio de Janeiro (PPGM-IGEO-CCMN-UFRJ).

MCGINLEY, J.A. A diagnosis of Alpine lee cyclogenesis. Monthly Weather Review, v. 10, p. 1271-1287, 1982.

MCTAGGART-COWAN, R.; BOSART, L.F.; DAVIS, C.A.; ATALLAH, E.H.; GYAKUM, J. R.; EMANUEL, K.A. Analysis of Hurricane Catarina (2004). Monthly Weather Review, v. 134, p. 3029-3053, 2006.

MCTAGGART-COWAN, R.; DAVIES, E.L.; FAIRMAN JR., J.G.; GALARNEAU JR. T.J.; SCHULTZ, D.M. Revisiting the $26.5^{\circ} \mathrm{C}$ Sea Surface Temperature Threshold for Tropical Cyclone Development. Bulletin of the American Meteorological Society, v. 96, 1929-1943, 2015.

MUNDELL, D.B. Prediction of tropical cyclone rapid intensification events. Master Dissertation, Dept. of Atmospheric Science, Colorado State University, 1990.
NHC - NATIONAL HURRICANE CENTER. Tropical Cyclone Climatology. Disponível em http://www.nhc.noaa.gov/climo/. Acesso em 11 de janeiro de 2016.

ORLANSKI, I.; KATZFEY, J. The life cycle of a cyclone wave in the Southern Hemisphere. 1. Eddy energy budget. Journal of the Atmospheric Sciences, v. 48, p. 1972-1998, 1991.

PALMÉN, E. Formation and development of tropical cyclones. In Proc. Tropical Cyclone Symp. Brisbane, pp. 213-231. Bur. Meteorol., Melbourne, Australia, 1956.

PALMÉN, E.; NEWTON, C.W. Atmospheric Circulation Systems: Their Structure and Physical Interpretation. New York: Academic Press, 603 p, 1969.

PETTERSSEN, S. Introduction to Meteorology. 1a ed., McGraw-Hill Book Company, New York, 1941.

PETTERSSEN, S. A general survey of factors influencing development at sea level. Journal of Applied Meteorology, v. 12, p. 36-42, 1955.

PETTERSSEN, S. Weather analysis and forecasting. New York: McGraw Hill, 1956.

PETTERSSEN, S.; DUNN, G.E.; MEANS, L.L. Report of an experiment in forecasting of cyclone development. Journal of Meteorology, v. 12, p. 58-67, 1955.

PEZZA, A.B.; SIMMONDS, I. The First South Atlantic Hurricane: Unprecedented Blocking, Low Shear and Climate Change. Geophysical Research Letters, v. 32, L15712, 2005.

PIVA, E.; MOSCATI M. C.L.; GAN M.A. Papel dos fluxos de calor latente e sensível em superfície associado a um caso de ciclogênese na costa leste da América do Sul. Revista Brasileira de Meteorologia, v. 23, n. 4, p.450-476, 2008.

PIVA, E.; GAN, M.A.; The Role of Latent and Sensible Heat Fluxes in an Explosive Cyclogenesis over the South American East Coast. Journal of the Meteorological Society of Japan, v. 86, p. 1-27, 2011.

RAMAGE, C.S. Hurricane development. Journal of Meteorology, v.16, p. 227-237, 1959.

RAMSAY, H.; CAMARGO, S.J., KIM, D. Cluster analysis of tropical cyclone tracks in the Southern Hemisphere. Climate Dynamics, v. 39, n. 3, pp. 897-917, 2012.

RANDEL, W.J.; STANFORD, J.L. The observed life cycle of a baroclinic instability. Journal of the Atmospheric Science, v. 42, n. 13, p. 1364-1373, 1985 .

REBOITA, M.S.; IWABE, C.; DA ROCHA, R.P.; AMBRIZZI, T. Análise de um ciclone semi-estacionário na Costa Sul do Brasil associado a bloqueio atmosférico: o Evento de 02 a 06 Maio de 2008. Revista Brasileira de Meteorologia, v. 24, n.4, p. 407-422, 2009.

REBOITA, M.S.; DA ROCHA, R.P.; AMBRIZZI, T; SUGAHARA, S. South Atlantic Ocean Cyclogenesis Climatology Simulated by Regional Climate Model (RegCM3). Climate Dynamics, v. 35, p. 1331-1347, 2010.

REBOITA, M.S.; DA ROCHA, R.P.; AMBRIZZI, T. Dynamic and climatological features of cyclonic developments over southwestern South Atlantic Ocean. Horizons in Earth Science Research, 6, Nova Science Publishers, pp. 135-160, 2012.

REBOITA, M.S.; DIAS PINTO, J.R.; DUTRA, L.M.M.; DA ROCHA, R.P. Synoptic Analysis of Subtropical Cyclones over the South Atlantic Ocean. In: PASI on Atmospheric Processes in Latin America and the Caribbean: Obser- 
vations, Analysis, and Impacts. 27 de maio a 07 de junho de 2013, Cartagena, Colômbia.

REBOITA, M.S.; DA ROCHA, R.P.; AMBRIZZI, T.; GOUVEIA, C.D. Trend and teleconnection patterns in the climatology of extratropical cyclones over the Southern Hemisphere Climate Dynamics, DOI 10.1007/s00382-014-2447-3, 2014.

RIEHL, H. On the formation of typhoons. Journal of Meteorology, v. 5, p. 247-64, 1948.

RUDEVA, I; GULEC, S.K. Climatology of Cyclone Size Characteristics and Their Changes during the Cyclone Life Cycle. Monthly Weather Review, v. 135, p. 2568-2587, 2007.

SCHULTZ, D.M.; KEYSER, D.; BOSART, L.F. The effect of largescale flow on low- level frontal structure and evolution in midlatitude cyclones. Monthly Weather Review, v. 126, p. 1767-1791, 1998.

SCHULTZ, D. M.; WERNLI, H. Determining Midlatitude Cyclone Structure and Evolution from the Upper-Level Flow. 2001. Disponível em: http://www.cimms.ou.edu/ schultz/papers/marwealog.html. Acesso em 15 de janeiro de 2015.

SELUCHI, M.E.; CALBETE, N.O.; ROZANTE, R. Análisis de un desarrollo ciclónico en la costa oriental de América del Sur. Revista Brasileira de Meteorologia, v. 16, p. 51-65, 2001.

SHAPIRO, M.A.; KEYSER, D. Fronts, jet streams and the tropopause. Extratropical Cyclones, The Erik Palmén Memorial Volume, C. W. Newton and E. O. Holopainen, Eds., American Meteorological Society, p. 167-191, 1990.
SHEPHERD, J.M.; KNUTSON, T. The current debate on the linkage between global warming and hurricanes. Geography Compass, v. 1, p. 1-24, 2007.

SIMMONDS, I.; KEAY, K. Mean Southern Hemisphere Extratropical Cyclone Behavior in the 40-year NCEP-NCAR reanalysis. Journal of Climate, v. 13, p. 873-885, 2000a.

SIMMONDS, I.; KEAY, K. Variability of Southern Hemisphere extratropical cyclone behavior, 1958-97. Journal of Climate, v. 13 , p. 550-561, 2000b.

SINCLAIR, M.R. An objective cyclone climatology for the Southern Hemisphere. Monthly Weather Review, v. 122, p. 2239-2256, 1994.

SINCLAIR, M.R. A climatology of cyclogenesis for the Southern Hemisphere. Monthly Weather Review, v. 123, p. 1601-1619, 1995.

SUGI, M.; NODA, A.; SATO, N. Influence of the global warming on tropical cyclone climatology: An experiment with the JMA global model. Journal of the Meteorological Society of Japan, v. 80, p. 249-272, 2002.

SUTCLIFFE, R.C. A contribution to the problem of development. Quarterly Journal of the Royal Meteorological Society, v. 73, p. 370- 383, 1947.

TROUP, A.J.; STRETEN, N.A. Satellite-Observed Southern Hemisphere Cloud Vortices in Relation to Conventional Observations. Journal of Applied Meteorology, v. 11, p. 909-917, 1972.

ZHAO, M.; HELD, I.M.; LIN, S.J.; VECCHI, G.A. Simulations of global hurricane climatology, interannual variability, and response to global warming using a $50 \mathrm{~km}$ resolution GCM. Journal of Climate, v. 22, n. 4, p. 6653-6678, 2009.

This is an Open Access article distributed under the terms of the Creative Commons Attribution Non-Commercial License which permits unrestricted non-commercial use, distribution, and reproduction in any medium provided the original work is properly cited. 